\title{
Elucidating the vertical transport of microplastics in the water column: A review of sampling methodologies and distributions
}

\author{
Liu, K
}

http://hdl.handle.net/10026.1/18316

10.1016/j.watres.2020.116403

Water Research

Elsevier BV

All content in PEARL is protected by copyright law. Author manuscripts are made available in accordance with publisher policies. Please cite only the published version using the details provided on the item record or document. In the absence of an open licence (e.g. Creative Commons), permissions for further reuse of content should be sought from the publisher or author. 


\section{2 a review of sampling methodologies and distributions}

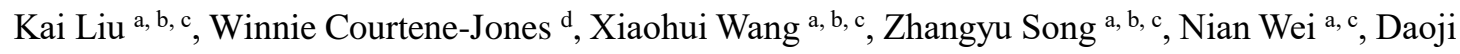
$\mathrm{Li}^{\text {a, b, c, * * }}$
a: State Key Laboratory of Estuarine and Coastal Research, East China Normal University, 500 Dongchuan Road, Shanghai 200241, China

b: Plastic Marine Debris Research Center, East China Normal University, 500 Dongchuan Road, Shanghai 200241, China

c: Regional Training and Research Center on Plastic Marine Debris and Microplastics, IOCUNESCO, 500 Dongchuan Road, Shanghai 200241, China

d: Marine Biology and Ecology Research Centre, School of Marine Science and Engineering, University of Plymouth, Drake Circus, Plymouth, Devon PL4 8AA, United Kingdom

*Corresponding author

Abstract: There have been numerous studies that have investigated floating microplastics (MPs) in surface water, yet little data are currently available regarding the vertical distribution in the water column. This lack constrains our ability to comprehensively assess the ecological effects of MPs and develop further policy controls. In this study, we reviewed current progress of sampling methodologies, the distribution patterns, and the physiochemical properties of MPs throughout the water column. Three sampling protocols were identified in this study: bulk, net and submersible pump/in-situ sampling. In different regions, the vertical patterns of MPs in the water column varied with depth, which is possibly related to the morphological characteristics, polymeric densities, and biofouling of the MPs. The results of this review revealed that fibrous and fragmented MPs comprised over $90 \%$ of the total MPs by quantity, of which fibrous MPs constituted the majority (43\%-100\%). In addition, polyethylene terephthalate, polyamide, polyethylene, polyvinyl chloride, and polypropylene have been widely identified in previous studies. To minimize the impact caused by various sampling protocols, the use of a volume gradient trail experiment and a unified mesh 
size of $60-100 \mu \mathrm{m}$ for the initial concentration are recommended according to the results of this review. Given the limited knowledge regarding the vertical transport of MPs in the water column, harmonized sampling methods should first be developed. The mechanisms of this process can be separately considered for different water bodies, such as freshwater systems, coastal waters, and pelagic zones. The presence of these anthropogenic pollutants in the water column poses a threat to the largest but most vulnerable habitats of life on earth, and hence they merit further investigation.

Keywords: water column; microplastics; sampling methodology; vertical distribution; transport

\section{Introduction}

The ubiquitous presence of microplastics (MPs) in the ocean (Cole et al., 2011; Lusher et al., 2015), as well as in watersheds (Dris et al., 2015; Fan et al., 2019) worldwide, is now well established. The global distribution of MPs within surface waters has been well demonstrated using surface trawls in several studies (Moore et al., 2008; Cózar et al., 2014; Cózar et al., 2017; Isobe et al., 2017). The floating stock of MPs in 2010 was estimated to be approximately 0.25 MT (Eriksen et al. 2014), which is much smaller than the estimate of 4.8 to 12.7 MT for the amount of plastics being released into the ocean (Jambeck et al., 2015). The large difference between the estimated input and the observed MPs within the upper ocean imply that there are processes that alter the distribution of MPs. Some studies have suggested that the missing portion is possibly attributable to MPs sinking to the seafloor (Woodall et al., 2014; Courtene-Jones et al., 2020). Courtene-Jones et al. (2020) reported the pervasive presence of MPs in a sediment core obtained from the Rockall Trough, and a statistically significant historical accumulation was found.

The oceanic water column is the largest ecosystem on earth, and could potentially be a huge reservoir of missing plastics from the earth's surface. However, to date, the vertical distribution of 
51 MPs and the mechanisms involved during the sinking process are largely unknown. In addition, these MPs could be intentionally or unintendedly ingested by aquatic organisms (Sussarellu et al, 2016; Galloway et al., 2017), potentially threating billions of marine lives. Nevertheless, without robust data on MP abundance in the water column, the impact on these species cannot be easily ascertained.

This study reviewed the current progress of MPs research in the water column, and specifically, this study focused on the vertical distribution from the surface to the deeper environment and related sampling methods. However, the depth criteria for these studies have not been limited to hundreds or thousands of meters, and only those that have primarily studied the vertical occurrence of MPs in the aquatic environment were considered in this review. Furthermore, this review aimed to identify the knowledge gaps in sampling methodologies, distribution patterns, and vertical transport mechanisms from the surface water. Additionally, this review is expected to provide a methodological introduction for subsequent studies to acquire representative samples and to decipher the transport patterns of MPs into the deeper ecosystem.

\section{Database and search criteria}

The data used in this study were collected from the Web of Science on July $3^{\text {rd }}, 2020$. First, the search string was defined as ((microplastic* OR plastics OR plastic microlitter OR synthetic polymer) AND (water column OR water depth OR subsurface* OR water layers OR sampling depth OR vertical distribution) AND (water)). All of the database ranging from 1990 to 2020 was searched under the advanced research mode with "Topic" as the field tag. A total of 2,220 results were preliminarily verified, and then most of the irrelevant records $(\mathrm{N}=1,372)$ according to targeted research areas (environmental science ecology and oceanography) were excluded. The remaining 
848 records was exported into a plain text format with the titles and abstracts.

These studies were further screened according to the content of the abstracts, and the selection criteria were as follows: (1) They should be from peer-reviewed journals and original research articles from field work. (2) For regional investigations, the depth intervals should be reported in these studies, and at least two layers of water columns should be sampled. (3) Those with only one sampling depth were not included in the spatial patterns analysis, except for the sampling methodology summary. Overall, this review primarily focused on the sampling methodologies and vertical distribution of MPs in the water columns. Eventually, a total of 31 references were identified. These studies are summarized in Table 1, and the general geolocation of the sampled water columns are mapped in Figure 1A.

\section{Sampling methodologies and sample analyses}

By categorizing by sampling methodology, these studies were generally divided into bulkwater sampling (Bagaev et al., 2017; Bagaev et al., 2018; Cordova et al., 2018; Dai et al., 2018; Di Mauro et al., 2017; Ding et al., 2019; Kanhai et al., 2018; Peng et al., 2018), net sampling (Lattin et al., 2004; Lenaker et al., 2019;) and submersible pumps/in-situ sampling (Choy et al., 2019; Liu et al., 2019; Song et al., 2018; Zobkov et al., 2019) (Fig.1).

\subsection{Bulk water sampling}

Typically, bulk water sampling allows for the collection of a defined volume of water at specific water layers. This method offers an effective technique to sample bulk water samples during a limited time duration, which could be useful in some restricted areas, especially in shallow waters. The sampling devices primarily included a plexiglass water sampler (Ding et al., 2019), a Rosette sampler system (CTD sampler) (Bagaev et al., 2017; Bagaev et al., 2018; Cordova et al., 2018; Dai 
et al., 2018; Di Mauro et al., 2017; Kanhai et al., 2018), and the lander system (Peng et al., 2018).

For instance, by using the plexiglass water sampler (Fig.1C), Ding et al (2019) collected seawater samples at depths of $1 \mathrm{~m}, 5 \mathrm{~m}$, and $15 \mathrm{~m}$ in reef flats, North Reef, and the Yongle Atoll. This device is particularly useful and convenient for MPs collection in shallow waters with relatively low flow velocities, but would not be applicable to deeper aquatic environments. Specifically, it is usually made of acrylic materials and can be fragile when subjected to intensified external forces. In addition, the Rosette sampler system equipped with conductivity-temperaturedepth sensors (CTD) (Fig. 1B), was adopted to collect water samples at various depths in marginal seas (Dai et al., 2018) and pelagic zones (Kanhai et al., 2018; Peng et al., 2018). It is typically comprised of a set of Niskin bottles (8-12 L), a stainless-steel frame, and attached CTD sensors at the bottom, which can sample water from over 6,800 $\mathrm{m}$ in depth. Moreover, Niskin bottles have also been fitted on a lander system to collect bottom water near the seafloor (Fig.1G) (Peng et al., 2018). Although it would be efficient to obtain MP samples at various layers of water samples for every deployment, only limited volumes of seawater can be collected at each depth using Niskin bottles.

For the pretreatment and analysis of the MP samples, generally, most $(\mathrm{N}=10)$ of the studies $(\mathrm{N}=13)$ reported that seawater samples collected using bulk sampling (plexiglass water sampler, CTD sampler, and the lander system) were directly filtrated, especially for the smaller volume collected samples (Table 1). MPs on the filters were retained and were visually examined using stereomicroscopy. In addition, some researchers would first remove the organic matter in the samples using digestive reagents and re-filtrate the MP samples before polymeric identification (Dai et al., 2018).

\subsection{Net sampling}


A range of techniques with this mechanism have been used to collect water column MP samples, which primarily included plankton trawls (Baini et al., 2018; Di Mauro et al., 2017; Doyle et al., 2011; Lefebvre et al., 2019; Goldstein et al., 2013; Gorokhova, 2015; Güven et al., 2017; Oztekin et al., 2015; Rowley et al., 2020), multi-net trawls (Kooi et al., 2016; Kukulka et al., 2012; Lattin et al., 2004; Lenaker et al., 2019; Liedermann et al., 2018; Reisser et al., 2015), and multiple opening and closing nets (Egger et al., 2020).

Vertical or oblique trawling was used to collect plankton samples in the water column, and this was also applied to collect suspended MPs (Fig.1E) (Di Mauro et al., 2017; Frias et al., 2014; Gorokhova, 2015). Gorokhova (2015) used a plankton net to investigate the seasonal variation of MPs in the water column of the Baltic Sea down to $100 \mathrm{~m}$ in depth. This sampling protocol allowed for the integration of the monitoring for MP pollution and the plankton community. However, this method was unable to collect samples at specific water depths, and failed to differentiate the vertical variation in the entire column. To attempt to overcome these challenges, there has been an effort to simultaneously collect plastic debris in the upper aquatic environment using a multi-net trawl (Fig.1F) (Kooi et al., 2016; Kukulka et al., 2012; Lattin et al., 2004; Lenaker et al., 2019; Liedermann et al., 2018; Reisser et al., 2015). During the investigation, Lenaker et al. (2019) deployed five neuston nets at depths ranging from 0.4 to $12.7 \mathrm{~m}$ in the Milwaukee River Basin and synchronously sampled various layers of the water column. While this is a highly efficient sampling method that would contribute a comparable result with previous studies that used surface trawls, technical limitations only enable it to be applied in the upper aquatic environment. It would be difficult to be applied at thousands of meters in depth.

Similar with the sample pretreatment used in the bulk sampling, for samples collected using 
139

plankton nets ( $\mathrm{N}=11$, multiple opening and closing net has also been included) (Baini et al., 2018; Di Mauro et al., 2017; Doyle et al., 2011; Goldstein et al., 2013; Gorokhova, 2015; Güven et al., 2017; Lefebvre et al., 2019; Oztekin et al., 2015; Rowley et al., 2020), most of researchers visually observed the MPs under stereomicroscopy in most of the studies $(\mathrm{N}=9)$. Only two studies performed on the River Thames (Rowley et al., 2020) and in Turkish coastal waters (Güven et al., 2017) digested organics to facilitate MP identification.

\subsection{Submersible pumps and in-situ collection}

The third sampling protocols for MPs in water columns included submerged pumps (Ng and Obbard, 2006; Song et al., 2019; Zobkov et al., 2019), sediment traps (Ballent et al., 2016; Reineccius et al., 2020), and in-situ filtration devices (Choy et al., 2019; Liu et al., 2019; Tekman et al., 2020). In addition, an underway water intake system was also used to collect subsurface seawaters at a specific depth (Lusher et al., 2015; Ryan et al., 2020).

Typically, submersible pumps have been used to quantify neustonic MPs in the surface water (Zhao et al., 2014) (Fig.1D). Now, it has been also successfully applied these pumps to water samples from substance waters in a coastal zone (Song et al, 2019; Zobkov et al., 2019). Using this method, Song et al. (2019) sampled $100 \mathrm{~L}$ of water from various depths $(0.20-58 \mathrm{~m})$ at eight sites in Korean coastal waters. In addition, a modified submerged pump by Zobkov et al. (2019) was also used to collect water from the water column of the Baltic Sea. In their design, this device could directly pump water from specific layers to the filters. Overall, this method could be more flexible in the field than the CTD sampler and useful in epibenthic watersheds, especially for freshwater systems and coastal waters. However, similar to the plexiglass water sampler, a sampling campaign 
161

162

using submersible pumps could also be limited by hydraulic conditions, and sampling depths could vary according to the sea state.

A further method used to sample MPs in the water column was in-situ collection, which can directly filtrate or collect MPs samples from large volumes of water obtained from specific layers. With this method, it is possible to obtain a concentrated sample from hundreds of cubic meters of water at different depths down to thousands of meters (Choy et al., 2019; Liu et al., 2019; Tekman et al., 2020). This could enable researchers to directly obtain a filter or net with MPs. This promising technology enables the direct filtration of MPs from the surrounding water at high efficiency. Liu et al. (2019) first used a plankton pump to in-situ filtrate the water column of the East China Sea (Fig.1H), and the volume impact on the MP quantification was identified by filtrating the seawater in the gradient. Choy et al. (2019) modified an in-situ filtration device and equipped it on an ROV to collect MPs at nearshore and offshore sites of Monterey Bay, California (Fig.1I). In general, the instrument used in the aforementioned two studies sampled exceptional large volumes at every deployment according to the desired research plan, and compared with bulk sampling, it could ensure data consistency with surface trawling. In addition, a recent study reported that an in-situ filtration device was attached on a CTD sampler to filter MP samples from water columns near the HAUSGARTEN observatory (Tekman et al., 2020). Nevertheless, these instruments could only obtain one MP sample at a time, and therefore, they have to be retrieved when the sample campaign is finished. Additional treatment or preparation (filter collection or washing process) needs to be made before the next deployment.

In addition, sediment traps have also been used to collect MP samples from Humber Bay (Ballent et al., 2016), and in this study that lasted six months, four cylinders of sediment traps were 
183

184

collected from $2 \mathrm{~m}$ in depth above the lake bed. Recently, Reineccius et al (2020) placed sediment traps at 2,000 and 3,000 m depth in the North Atlantic Subtropical gyre to monitor the deposition flux of microfibers. These devices could directly capture the deposited MPs from the upper layers of water columns. This allows for the assessment of the sinking behaviors and vertical flux of MPs. However, these sampling instruments are typically fixed at a certain water depth, and the MP sinking behaviors of every water layer are difficult to quantify.

A total of 8 studies used these methods (submersible pumps: $\mathrm{N}=3$; underway water intake system: $\mathrm{N}=2$; in-situ filtration device: $\mathrm{N}=3$ ) to collect MP samples from water columns, and over half of them $(\mathrm{N}=5)$ could directly verify the existence of MPs under stereomicroscopy without the need to remove organic matter from the samples (Table. 1). In addition, of four studies that used digestion pretreatment (Liu et al., 2019; Song et al., 2018; Tekman et al., 2020; Zobkov et al., 2019), Song et (2019) applied a density separation using a saturated $\mathrm{NaCl}$ solution to extract MP particles from Korea coastal waters.

\section{Vertical distribution of MPs abundance}

Until now, few studies have considered the vertical pattern of MPs, and unharmonized sampling methods have inevitably led to noncomparable results. In addition, regional differences (e.g., emission sources, hydraulic conditions, and biological interactions) could also have hindered an understanding of the vertical transport of MPs from the surface to deep ocean water. To facilitate this comparison, in this review, the quantities of MP pollution in the water column were only compared with studies that used the same sampling protocols within the similar waters categories

(e.g., freshwater systems, coastal waters, and pelagic zones) according their geolocation. Owing to the differences in sampling methods and regions, the vertical distribution of MPs found in the studies 
were separately analyzed.

\subsection{Freshwater systems}

Unlike coastal waters, the hydraulic conditions of freshwater systems are less dynamic, and a freshwater catchment could be highly polluted due to the proximity to anthropogenic activities (Wang et al., 2019). Typically, MPs were more abundant in the surface water once discharged from an estuarine system, as Lenaker et al. (2019) described. An exponential decreasing trend of MPs with water depth was found in freshwater systems, but no statistical difference was observed (Lenaker et al., 2019). This pattern could possibly result from biofouling and biofilm on the MPs that would contribute to sinking due to a density increase (Kooi et al., 2017). It was also found that these MPs were sampled using multi-net trawls with a mesh size of $333 \mu \mathrm{m}$ (Lenaker et al., 2019).

Therefore, the actual abundance of MPs could possibly be several orders of magnitude higher because of progressive fragmentation (Cózar et al., 2014). In the current review, the general trend of MPs in vertical direction was only focused on. It was also found that there was insufficient studies of MPs in the water column of freshwater systems and their distribution mechanisms merit further study.

\subsection{Coastal waters}

For the MP studies performed in coastal seas that used bulk sampling, a significant exponential decrease between the water depth and the MP abundance was reported in the literature (Dai et al., 2018; Song et al., 2018; Zobkov et al., 2019) $\left(\mathrm{R}=0.42, P=2.08 \mathrm{E}^{-7}<0.01\right)$, which is similar to a previous numerical model developed by Reisser et al. (2015). Reisser et al. (2015) sampled the top $6 \mathrm{~m}$ of the water column in the North Atlantic accumulation zone and also found an exponential decrease in MP concentrations with increasing depth. However, a different pattern was observed 
using an in-situ filtration technique (Choy et al., 2019; Liu et al., 2019), and a quadratic distribution between the sampling depth and MP abundance was statistically revealed in coastal seas $(\mathrm{R}=0.76$, $P=0.02<0.05$ ). In summary, a higher MP content was found in the subsurface of the water column by using in-situ filtration methods. The inconsistent distribution found using these two sampling methods could be due to many factors such as sampling methods, water mass structure, MP pollution sources, and the sinking velocity of MPs. Owing to the proximity to terrestrial sources in distance, MP emissions could be assumed to be consistent, unless an accidental leakage occurred. Therefore, this phenomenon could primarily result from the remaining factors. While it is logical that more abundant MPs would be found in nearshore surface waters due to the proximity to sources (Song et al., 2018), in fact, the studies revealed that a higher abundance of MPs could be detected in subsurface waters in offshore areas. For example, Dai et al. (2018) collected samples from a total of six water columns from the Bohai Sea and reported a relatively higher abundance of MPs in the subsurface samples from locations further away from the coast. Indeed, similar findings were also observed in the Baltic Sea, where Zobkov et al. (2019) found elevated MP abundances in the subsurface layers, suggesting the importance of a density stratification impact on the vertical distribution.

\subsection{Pelagic zones}

Until now, knowledge of the vertical distribution of MPs in the pelagic zone has been limited, and few studies are currently available. Generally, floating MPs would be subjected to physical mixing (Reisser et al., 2015) and biofouling (Goldstein et al., 2014), which would eventually sink to deeper layers. In the surface water, the transport of MPs would be greatly influenced by wind and waves (van Sebille et al., 2020), resulting in high frequency vertical displacements. While water 
depth could be very critical in shaping the distribution patterns of MPs, the distance to the coast has also been reported to have a relationship with their vertical distribution. Some studies have revealed that higher quantities of MPs have indeed been detected nearshore, compared to observations near the Arctic (Kanhai et al., 2018).

When sinking into deeper layers, MPs would be subjected to the structure of the water mass and driven by global thermohaline circulation. In particular, the pycnocline, which could create a density barrier, could possibly hinder the vertical transport of MPs and allow them to suspend for extended times in haloclines or thermoclines. This hypothesis was preliminarily tested in the water column of the Baltic Sea (Zobkov et al., 2019), and MPs were found to be temporally retained in the density-gradient layers during the vertical transport.

After the long-term transport of MPs in the water column, partial MPs could eventually deposit on the seafloor, and a higher abundance of MPs on the seafloor has been assumed to be the ultimate sink for marine plastic debris (Bergmann et al., 2017; Woodall et al., 2014). It has been predicted that a higher abundance of MPs would be both isolated in the upper water environment and in bottom water near the seafloor (Kanhai et al., 2018; Peng et al., 2018). In addition, a recent study indicated that bottom currents could also strongly control the movement of MPs at the seafloor and regulate their vertical distribution (Kane et al., 2020). As a vital conveyor of nutrients and oxygen, near-bed thermohaline currents could also play a key role in the ultimate fate of marine MPs.

\section{Morphological and chemical properties of MPs}

\subsection{Morphological characteristics}

Fiber, fragment, granule, foam, film, and microbead shaped MPs have been isolated from the 
water column, and the detailed compositions are summarized in Table.2. These morphological appearances of MPs in the water column have also been observed in many studies of surface waters from inland freshwater systems, catchment runoff, coastal areas, and pelagic ocean areas (Desforges et al., 2014; Free et al., 2014; Isobe et al., 2015; Gove et al., 2019). In the studies evaluated in this review (Table 2), fibrous and fragmented MPs comprised over $90 \%$ of the total MPs by quantity, of which fibrous MPs constituted the majority (43\%-100\%) over plastic fragments, with the exception of results from the East China Sea and the Korean coastal waters, where a relatively higher proportion of fragmented MPs were detected (Liu et al., 2019; Song et al., 2018). A possible explanation for this phenomenon could be the joint effects of sampling protocols and regional differences. Hence, this merits further study.

A previous study validated the shape effect on MPs that sink to a deeper environment, and fiber, fragment, and sphere shaped MPs displayed a distinct sinking pattern (Khatmullina and Isachenko, 2017). However, fibrous MPs tended to sink in a direction perpendicular to their longest dimension, and cylinder MPs exhibited some movements, such as, rotation, oscillation, and tumbling. Generally, it was also found that were some patterns to the shape-based distribution throughout the water column, and these are summarized in Table 2. Some studies reported a negative relationship between MP size and sampling depth in coastal seas (Dai et al., 2018; Zobkov et al., 2019). For instance, Dai et al. (2018) mentioned that the relative proportion of fibrous MPs was lower in subsurface waters than in surface samples and the numerical proportion of MPs $<300 \mu \mathrm{m}$ would increase with water depth. This suggested a size-dependent removal mechanism. Similarly, during an investigation of the Baltic Sea (Zobkov et al., 2019), MP size was found to exponentially decrease with depth. However, significant shape variation has only been found in nearshore water columns, and shape 
293

294

compositions along the vertical gradient did not vary significantly in the offshore area of the Milwaukee River Basin (Lenaker et al., 2019). This difference could possibly be ascribed to the stronger physical mixing in the coastal zone than in freshwater ecosystems, and biofouling could primarily contribute to the removal of MPs from the surface in freshwater systems.

\subsection{Polymer composition}

An analysis of the polymeric types was performed in 17 of the studies (Baini et al., 2018; Choy et al., 2019; Cordova et al., 2018; Dai et al., 2018; Di Mauro et al., 2017; Ding et al., 2019; Egger et al., 2020; Kanhai et al., 2018; Lefebvre et al., 2019; Lenaker et al., 2019; Lusher et al., 2015; Ng and Obbard, 2006; Peng et al., 2018; Rowley et al., 2020; Song et al., 2018; Tekman et al., 2020; Zobkov et al., 2019), and a total of 37 polymer types were verified in the water column (Table.3). PE, PP, PET, PA, and PVC MPs have been widely identified in previous studies, of which PET MPs ranked first in quantity. Overall, the polymeric composition of MPs from the surface to the bottom has been barely reported on, and most of the studies have only reported on the general composition of all obtained MPs, regardless of sampling depth.

A recent investigation revealed the gradient distribution of polymers with depth, suggesting a partial contribution of polymer density in the vertical transport in the water column (Lenaker et al., 2019). This finding was consistent with a previous report on the seafloor (Woodall et al., 2014), where negative buoyant MPs were speculated to sink eventually. In research of the Milwaukee River Basin (Lenaker et al., 2019), the content of MPs with lower densities decreased with increasing sampling depth, and higher density MPs (PA, PAN, PVAc, and PET) displayed the opposite trend. Similarly, in the Bohai Sea, MPs with higher densities (e.g., PET and PVC) were found in the deeper layers of the water column (Dai et al., 2018). However, during the analysis, they also found PE MPs, 
which have a density less than water, in the benthic sediment, suggesting that the sinking mechanism of MPs could be multifactorial. Additionally, the higher degradation on the surface of MPs from the deeper layers was imaged (Dai et al., 2018), implying the important contribution of biofouling. This biological process was observed using an in-situ feeding experiment by Katija et al. (2017). In this study, MPs incorporated in fecal pellets of giant larvaceans quickly sank to the deeper environment. Moreover, this density-dependence theory was also preliminarily confirmed by findings from Korean coastal waters (Song et al., 2018), where researchers found that MPs with higher densities would be typically detected in the subsurface of water columns. Interestingly, in this study, MPs with PP and PE polymeric compositions also prevailed throughout the water column. While, in fact, it is common for MPs with higher densities than water to quickly sink to deeper layers, there is also an interesting fact that plastic debris with less densities prevail throughout the water column. A density-dependent hypotheses could be useful to explain the fast sinking of MPs with higher densities than water, yet little is known about the later process of how low-density MPs transport into the deeper layers. Constrained by the available data, it can only be speculated that physical mixing (Isobe et al., 2015; Reisser et al., 2015) could be significant to the removal of floating plastic debris from surface waters. Physical mixing triggered by wind and waves was observed in a previous study by Reisser et al. (2015), and small-sized plastic debris would be susceptible to this vertical transport in the upper aquatic environment. However, the vertical transport of MPs in the water column is not merely dependent on polymeric densities, and further implications due to MP shapes and the water mass structure were also highlighted in a relevant study (Kowalski et al., 2016).

\section{Outlook for following studies}




\subsection{Harmonized sampling methodology}

While neustonic MPs have been well studied (Cózar et al., 2014; Isobe et al., 2019; Thompson et al., 2004), knowledge of vertical transport in the water column is presently limited. To acquire comparable data, a harmonized sampling methodology would be of great importance and needs to be developed and studied. However, to date, various sampling methods (e.g., CTD samplers, submerged pumps, multi-net trawls, in-situ filtration devices, and sediment traps) have been utilized, and this inevitably leads to noncomparable results among studies. To date, several guidelines regarding the sampling protocols of MPs in the water column have been mentioned (Cheshire et al., 2009; GESAMP, 2019; Galgani et al., 2011; Masura et al., 2015), but only general instructions have been provided, or it has been barely referred to. For instance, the UNEP/IOC guidelines primarily focus on the sampling methodology of marine litters on beaches, surface waters, and the seafloor (Cheshire et al., 2009), and trawling collection has been recommended for floating and benthic litters. While in the guidelines developed by GESAMP (2019), a series of sampling instruments (i.e., plankton nets, submerged pumps) were listed. Unfortunately, efficiency validations of these protocols have not been intensively evaluated. In addition, the impact of volume on MP quantification has been reported in a recent study (Liu et al., 2019; Lusher et al., 2014), and a more stable quantification would be obtained by using large-volume samples, which has been speculated to be vital to accurately reveal the MP occurrence. Similarly, Tamminga et al. (2018) found that the sample efficiencies of a manta trawl and bulk samples were not comparable, and a limited sample volume is insufficient to represent an entire water mass. In addition, the mesh size of trawls could be an unneglectable factor that would hinder the collection of representative samples (Hidalgo-Ruz et al., 2012). It is acknowledged in this review that it would be a great challenge to implement a 
unified sampling methodology among regional studies due to the availability and regional differences of sampling instruments. Therefore, it is proposed to conduct a volume gradient experiment prior to each investigation to reach the ideal volume of filtrated water, as described by Liu et al. (2019), especially for bulk sampling and water samples collected using submersible pumps. The primary reason for this trial experiment is to understand the heterogeneous distribution (both temporal and spatial) of MPs in aquatic environments. To validate the sampling volume, Lusher et al. (2014) collected $100 \mathrm{~L}, 250 \mathrm{~L}, 500 \mathrm{~L}, 1,000 \mathrm{~L}$, and 2,000 L water samples using a submerged pump and confirmed the ideal volume to be $2,000 \mathrm{~L}$. This significant impact of the sampling volume on MP quantification was also studied by Liu et al. (2019). They found that more stable results could be obtained when the volume of filtrated water when using an in-situ filtration device was $>8 \mathrm{~m}^{3}$.

To facilitate collection by bulk sampling, submersible pumps, and in-situ filtration, the use of 60-90 $\mu \mathrm{m}$ mesh size is also recommended in this review to obtain concentrated samples because 14 of 31 of the reviewed studies revealed that the size of isolated MPs are typically greater than $50 \mu \mathrm{m}$ (Table 1). In addition, a recent study also revealed the great importance of mesh size on MP quantification, and a smaller size $(100 \mu \mathrm{m})$ of the sampling trawls could lead to a ten-time higher abundance of MPs as opposed to a net with $500 \mu \mathrm{m}$ (Lindeque et al., 2020), suggesting the possible underestimation in previous work that used a Manta trawl $(330 \mu \mathrm{m})$. Nevertheless, in contrast, Ryan et al. (2020) found that a mesh size of $20 \mu \mathrm{m}-63 \mu \mathrm{m}$ only had a slight impact on MP quantification using bulk sampling. While smaller mesh size would ensure the capture ability of suspended MPs in the water, blockages by zooplankton and algae could also occur, especially in freshwater ecosystems and coastal waters, and therefore this should be carefully considered. These two studies revealed important issues regarding the accurate quantification of MPs in the field, and a 
381

combination of trawl sampling and bulk collection should be carefully considered in a future study. Moreover, a unified pretreatment of water samples could also be necessary to obtain a robust and replicable results, meriting further work and collaboration.

\subsection{Depletion mechanisms of plastic debris from surface waters}

Plastic debris depletion patterns from the surface remain unclear, but several hypotheses (i.e., physical and biological forces) for this process have been proposed (Cózar et al., 2014). This vertical movement could result from the joint effects of hydrodynamics (i.e., tidal motion, Ekman pumping, upwelling, downwelling, and turbulence-induced roll structures), plastic properties, and biointeractions, as van Sebille et al. (2020) summarized. In addition, the transport could also be influenced by water stratification, especially in estuaries (Zhao et al., 2019).

For instance, the sinking of floating MPs was speculated to have a close relationship with physical mixing by wind and waves in surface waters (Reisser et al., 2015), and the remaining transport could be ascribed to progressive fragmentation, ingestion by aquatic organisms, and biofouling (Andrady, 2011). In addition, these missing MPs could be also washed up onshore (Cózar et al., 2014), but the quantitative inventory remains unknown. Another hypothesis could be size selection depletion, where small-sized MPs from progressive fragmentation tend to sink faster. Size dependence removal of floating plastic debris from the surface of an open ocean was addressed in a previous investigation by Cózar et al. (2014). They speculated that progressive weathering would contribute to the fast sinking of MPs $<1 \mathrm{~mm}$ into deeper environments. This morphological contribution to the vertical transport was also highlighted by Khatmullina and Isachenko (2017), and distinct sinking behaviors of fibrous, cylindrical, and spherical MPs were observed in their experiment. 

microorganisms (Amaral-Zettler et al., 2020; Barnes, 2002), and the density would increase. This would lead to a loss of buoyancy over time. Based on the dynamic model of biofilm formation, Kooi et al. (2017) reported that the vertical transport of MPs could be related to MP density and size, and also facilitate the vertical displacement of MPs in the water column. In particular, algal aggregation would constantly increase the density of MPs, driving the MPs into the deeper environment observed in numerous species (Gove et al., 2019; Jâms et al., 2020; Sun et al., 2018). Ingested MPs are temporally stored in the digestive tracts of organisms and transferred along the food-webs during the vertical migrations of species, and then egested with excrement. This aspect merits further quantitative estimation.

\section{Conclusion}

Overall, various vertical patterns from the surface to the seafloor in different water bodies (i.e., freshwater systems, coastal waters, and pelagic zones) were found in this review, but their inner mechanisms could possibly differ among regions. However, inconsistent sampling methodologies

421 inevitably hinder researchers from adequately comparing processes among regions. In addition, this hinders an accurate estimate of the vertical transport of MPs from the upper aquatic environment.

423 Thus, in this review, a volume gradient experiment is recommended to obtain the ideal volume of 
minimize the sample volume and mesh size impact on MP quantification. A combination of bulk samples and net collection could be also be an effective method to reveal the sink patterns of MPs from the surface water. In addition, although several hypotheses and lab-based experiments have highlighted the contribution of morphological and polymeric density to the vertical transport, insufficient data in the field continue to constrain the understanding of the realistic transport of MPs. Given the ambiguity in the transport mechanisms, more field-based experiments should be conducted to more thoroughly understand the environmental behaviors by using validated sampling protocols. A separate consideration of transport processes in different habitats is suggested, and there is a need to quantify the contribution of the potential drivers of vertical transport.

\section{Acknowledgments}

This study was funded by the National Key Research and Development Program (2016YFC1402205), National Natural Science Fund of China (41676190), ECNU Academic Innovation Promotion Program for Excellent Doctoral Students (YBNLTS2019-007), and the ECNU "Future Scientist" Incubation Program to Kai Liu. We would like to extend our thank to the anonymous reviewers and dedicated editors for valuable suggestion to improve the quality of this manuscript.

\section{Reference}

Amaral-Zettler, L.A., Zettler, E.R., Mincer, T.J., 2020. Ecology of the plastisphere. Nat. Rev. Microbiol. 18(3), 139-151.

Andrady, A.L., 2011. Microplastics in the marine environment. Mar. Pollut. Bull. 62(8), 1596-1605.

Bagaev, A., Khatmullina, L., Chubarenko, I., 2018. Anthropogenic microlitter in the Baltic Sea water column. Mar. Pollut. Bull. 129(2), 918-923.

Bagaev, A., Mizyuk, A., Khatmullina, L., Isachenko, I., Chubarenko, I., 2017. Anthropogenic fibres 
in the Baltic Sea water column: Field data, laboratory and numerical testing of their motion. Sci. Total Environ. 599-600, 560-571.

Baini, M., Fossi, M.C., Galli, M., Caliani, I., Campani, T., Finoia, M.G., Panti, C., 2018. Abundance and characterization of microplastics in the coastal waters of Tuscany (Italy): The application of the MSFD monitoring protocol in the Mediterranean Sea. Mar. Pollut. Bull. 133, 543-552.

Barnes, D.K., 2002. Biodiversity: invasions by marine life on plastic debris. Nature 416(6883), 808809.

Bergmann, M., Wirzberger, V., Krumpen, T., Lorenz, C., Primpke, S., Tekman, M.B., Gerdts, G., 2017. High Quantities of Microplastic in Arctic Deep-Sea Sediments from the HAUSGARTEN Observatory. Environ. Sci. Technol. 51(19), 11000-11010.

Cheshire, A.C., Adler, E., Barbière, J., Cohen, Y., Evans, S., Jarayabhand, S., Jeftic, L., Jung, R.T., Kinsey, S., Kusui, E.T., Lavine, I., Manyara, P., Oosterbaan, L., Pereira, M.A., Sheavly, S., Tkalin, A., Varadarajan, S., Wenneker, B., Westphalen, G. 2009. UNEP/IOC Guidelines on Survey and Monitoring of Marine Litter. UNEP Regional Seas Reports and Studies, No. 186; IOC Technical Series No. 83: xii+120 pp.

Choy, C.A., Robison, B.H., Gagne, T.O., Erwin, B., Firl, E., Halden, R.U., Hamilton, J.A., Katija, K., Lisin, S.E., Rolsky, C., S. Van Houtan, K., 2019. The vertical distribution and biological transport of marine microplastics across the epipelagic and mesopelagic water column. Sci. Rep.Uk 9(1).

Cole, M., Lindeque, P., Halsband, C., Galloway, T.S., 2011. Microplastics as contaminants in the marine environment: A review. Mar. Pollut. Bull. 62(12), 2588-2597.

Cordova, M.R., Hernawan, U.E., 2018. Microplastics in Sumba waters, East Nusa Tenggara. IOP conference series. Earth and environmental science 162, 12023.

Courtene-Jones, W., Quinn, B., Ewins, C., Gary, S.F., Narayanaswamy, B.E., 2020. Microplastic accumulation in deep-sea sediments from the Rockall Trough. Mar. Pollut. Bull. 154, 111092.

Cozar, A., Echevarria, F., Gonzalez-Gordillo, J.I., Irigoien, X., Ubeda, B., Hernandez-Leon, S., Palma, A.T., Navarro, S., Garcia-de-Lomas, J., Ruiz, A., Fernandez-de-Puelles, M.L., Duarte, C.M., 2014. Plastic debris in the open ocean. P. Nat. Acad. Sci 111(28), 10239-10244.

Cozar, A., Marti, E., Duarte, C.M., Garcia-de-Lomas, J., van Sebille, E., Ballatore, T.J., Eguiluz, V.M., Gonzalez-Gordillo, J.I., Pedrotti, M.L., Echevarria, F., Trouble, R., Irigoien, X., 2017. The 
Arctic Ocean as a dead end for floating plastics in the North Atlantic branch of the Thermohaline Circulation. Sci Adv 3(4), e1600582.

Dai, Z., Zhang, H., Zhou, Q., Tian, Y., Chen, T., Tu, C., Fu, C., Luo, Y., 2018. Occurrence of microplastics in the water column and sediment in an inland sea affected by intensive anthropogenic activities. Environ. Pollut. 242, 1557-1565.

Desforges, J.W., Galbraith, M., Dangerfield, N., Ross, P.S., 2014. Widespread distribution of microplastics in subsurface seawater in the NE Pacific Ocean. Mar. Pollut. Bull. 79(1-2), 94-99.

Di Mauro, R., Kupchik, M.J., Benfield, M.C., 2017. Abundant plankton-sized microplastic particles in shelf waters of the northern Gulf of Mexico. Environ. Pollut. 230, 798-809.

Ding, J., Jiang, F., Li, J., Wang, Z., Sun, C., Wang, Z., Fu, L., Ding, N.X., He, C., 2019. Microplastics in the Coral Reef Systems from Xisha Islands of South China Sea. Environ. Sci. Technol. 53(14), 8036-8046.

Doyle, M.J., Watson, W., Bowlin, N.M., Sheavly, S.B., 2011. Plastic particles in coastal pelagic ecosystems of the Northeast Pacific ocean. Mar. Environ. Res. 71(1), 41-52.

Dris, R., Imhof, H., Sanchez, W., Gasperi, J., Galgani, F., Tassin, B., Laforsch, C., 2015. Beyond the ocean: contamination of freshwater ecosystems with (micro-)plastic particles. Environ. Chem. $12(5), 539$.

Egger, M., Sulu-Gambari, F., Lebreton, L., 2020. First evidence of plastic fallout from the North Pacific Garbage Patch. Sci. Rep.-Uk 10(1).

Eriksen, M., Lebreton, L.C.M., Carson, H.S., Thiel, M., Moore, C.J., Borerro, J.C., Galgani, F., Ryan, P.G., Reisser, J., 2014. Plastic Pollution in the World's Oceans: More than 5 Trillion Plastic Pieces Weighing over 250,000 Tons Afloat at Sea. Plos One 9(12), e111913.

Fan, Y., Zheng, K., Zhu, Z., Chen, G., Peng, X., 2019. Distribution, sedimentary record, and persistence of microplastics in the Pearl River catchment, China. Environ. Pollut. 251, 862-870.

Free, C.M., Jensen, O.P., Mason, S.A., Eriksen, M., Williamson, N.J., Boldgiv, B., 2014. High-levels of microplastic pollution in a large, remote, mountain lake. Mar. Pollut. Bull. 85(1), 156-163.

Frias, J.P.G.L., Otero, V., Sobral, P., 2014. Evidence of microplastics in samples of zooplankton from Portuguese coastal waters. Mar. Environ. Res. 95, 89-95.

Galgani, F., Hanke, G., Werner, S., \& Piha, H. 2011. MSFD GES technical subgroup on marine litter. Technical recommendations for the implementation of MSFD requirements. JRC Scientific and 
Technical Report, EUR, 25009, 93.

Galloway, T.S., Cole, M., Lewis, C., 2017. Interactions of microplastic debris throughout the marine ecosystem. Nat. Ecol \& Evol 1(5).

GESAMP. 2019. Guidelines or the monitoring and assessment of plastic litter and microplastics in the ocean (Kershaw P.J., Turra A. and Galgani F. editors), (IMO/FAO/UNESCOIOC/UNIDO/WMO/IAEA/UN/UNEP/UNDP/ISA Joint Group of Experts on the Scientific Aspects of Marine Environmental Protection). Rep. Stud. GESAMP No. 99, 130p.

Goldstein, M.C., Carson, H.S., Eriksen, M., 2014. Relationship of diversity and habitat area in North Pacific plastic-associated rafting communities. Mar. Biol. 161(6), 1441-1453.

Goldstein, M.C., Titmus, A.J., Ford, M., 2013. Scales of spatial heterogeneity of plastic marine debris in the northeast pacific ocean. Plos One 8(11), e80020.

Gorokhova, E., 2015. Screening for microplastic particles in plankton samples: How to integrate marine litter assessment into existing monitoring programs? Mar. Pollut. Bull. 99(1-2), 271-275. Gove, J.M., Whitney, J.L., McManus, M.A., Lecky, J., Carvalho, F.C., Lynch, J.M., Li, J., Neubauer, P., Smith, K.A., Phipps, J.E., Kobayashi, D.R., Balagso, K.B., Contreras, E.A., Manuel, M.E., Merrifield, M.A., Polovina, J.J., Asner, G.P., Maynard, J.A., Williams, G.J., 2019. Prey-size plastics are invading larval fish nurseries. P. Nat. Acad. Sci 116(48), 24143-24149.

Güven, O., Gökdağ, K., Jovanović, B., Kıdeyş, A.E., 2017. Microplastic litter composition of the Turkish territorial waters of the Mediterranean Sea, and its occurrence in the gastrointestinal tract of fish. Environ. Pollut. 223, 286-294.

Hidalgo-Ruz, V., Gutow, L., Thompson, R.C., Thiel, M., 2012. Microplastics in the Marine Environment: A Review of the Methods Used for Identification and Quantification. Environ. Sci. Technol. 46(6), 3060-3075.

Isobe, A., Iwasaki, S., Uchida, K., Tokai, T., 2019. Abundance of non-conservative microplastics in the upper ocean from 1957 to 2066. Nat. Commun. 10(1).

Isobe, A., Uchida, K., Tokai, T., Iwasaki, S., 2015. East Asian seas: A hot spot of pelagic microplastics. Mar. Pollut. Bull. 101(2), 618-623.

Jambeck, J.R., Geyer, R., Wilcox, C., Siegler, T.R., Perryman, M., Andrady, A., Narayan, R., Law, K.L., 2015. Plastic waste inputs from land into the ocean. Science 347(6223), 768-771.

Jâms, I.B., Windsor, F.M., Poudevigne-Durance, T., Ormerod, S.J., Durance, I., 2020. Estimating 
the size distribution of plastics ingested by animals. Nat. Commun. 11(1).

Kane, I.A., Clare, M.A., Miramontes, E., Wogelius, R., Rothwell, J.J., Garreau, P., Pohl, F., 2020. Seafloor microplastic hotspots controlled by deep-sea circulation. Science 368(6495), 1140-1145. Kanhai, L.D.K., Gårdfeldt, K., Lyashevska, O., Hassellöv, M., Thompson, R.C., O'Connor, I., 2018. Microplastics in sub-surface waters of the Arctic Central Basin. Mar. Pollut. Bull. 130, 8-18.

Katija, K., Choy, C.A., Sherlock, R.E., Sherman, A.D., Robison, B.H., 2017. From the surface to the seafloor: How giant larvaceans transport microplastics into the deep sea. Sci Adv 3(8), e1700715. Khatmullina, L., Isachenko, I., 2017. Settling velocity of microplastic particles of regular shapes. Mar. Pollut. Bull. 114(2), 871-880.

Kooi, M., Nes, E.H.V., Scheffer, M., Koelmans, A.A., 2017. Ups and Downs in the Ocean: Effects of Biofouling on Vertical Transport of Microplastics. Environ. Sci. Technol. 51(14), 7963-7971. Kooi, M., Reisser, J., Slat, B., Ferrari, F.F., Schmid, M.S., Cunsolo, S., Brambini, R., Noble, K., Sirks, L., Linders, T.E.W., Schoeneich-Argent, R.I., Koelmans, A.A., 2016. The effect of particle properties on the depth profile of buoyant plastics in the ocean. Sci. Rep.-Uk 6(1).

Kowalski, N., Reichardt, A.M., Waniek, J.J., 2016. Sinking rates of microplastics and potential implications of their alteration by physical, biological, and chemical factors. Mar. Pollut. Bull. 109(1), 310-319.

Kukulka, T., Proskurowski, G., Morét-Ferguson, S., Meyer, D.W., Law, K.L., 2012a. The effect of wind mixing on the vertical distribution of buoyant plastic debris. Geophys. Res. Lett. 39(7), n/a$\mathrm{n} / \mathrm{a}$.

Kukulka, T., Proskurowski, G., Morét-Ferguson, S., Meyer, D.W., Law, K.L., 2012b. The effect of wind mixing on the vertical distribution of buoyant plastic debris. Geophys. Res. Lett. 39(7), n/a$\mathrm{n} / \mathrm{a}$.

Lagarde, F., Olivier, O., Zanella, M., Daniel, P., Hiard, S., Caruso, A., 2016. Microplastic interactions with freshwater microalgae: Hetero-aggregation and changes in plastic density appear strongly dependent on polymer type. Environ. Pollut. 215, 331-339.

Lattin, G.L., Moore, C.J., Zellers, A.F., Moore, S.L., Weisberg, S.B., 2004. A comparison of neustonic plastic and zooplankton at different depths near the southern California shore. Mar. Pollut. Bull. 49(4), 291-294.

Lefebvre, C., Saraux, C., Heitz, O., Nowaczyk, A., Bonnet, D., 2019. Microplastics FTIR 
characterisation and distribution in the water column and digestive tracts of small pelagic fish in the Gulf of Lions. Mar. Pollut. Bull. 142, 510-519.

Lenaker, P.L., Baldwin, A.K., Corsi, S.R., Mason, S.A., Reneau, P.C., Scott, J.W., 2019. Vertical Distribution of Microplastics in the Water Column and Surficial Sediment from the Milwaukee River Basin to Lake Michigan. Environ. Sci. Technol. 53(21), 12227-12237.

Liedermann, M., Gmeiner, P., Pessenlehner, S., Haimann, M., Hohenblum, P., Habersack, H., 2018. A Methodology for Measuring Microplastic Transport in Large or Medium Rivers. Water-Sui. 10(4), 414.

Lindeque, P.K., Cole, M., Coppock, R.L., Lewis, C.N., Miller, R.Z., Watts, A.J.R., Wilson-McNeal, A., Wright, S.L., Galloway, T.S., 2020a. Are we underestimating microplastic abundance in the marine environment? A comparison of microplastic capture with nets of different mesh-size. Environ. Pollut. 265, 114721.

Lindeque, P.K., Cole, M., Coppock, R.L., Lewis, C.N., Miller, R.Z., Watts, A.J.R., Wilson-McNeal, A., Wright, S.L., Galloway, T.S., 2020b. Are we underestimating microplastic abundance in the marine environment? A comparison of microplastic capture with nets of different mesh-size. Environ. Pollut. 265, 114721.

Liu, K., Zhang, F., Song, Z., Zong, C., Wei, N., Li, D., 2019. A novel method enabling the accurate quantification of microplastics in the water column of deep ocean. Mar. Pollut. Bull. 146, 462-465. Long, M., Moriceau, B., Gallinari, M., Lambert, C., Huvet, A., Raffray, J., Soudant, P., 2015. Interactions between microplastics and phytoplankton aggregates: Impact on their respective fates. Mar. Chem. 175, 39-46.

Lusher, A.L., Burke, A., O Connor, I., Officer, R., 2014. Microplastic pollution in the Northeast Atlantic Ocean: Validated and opportunistic sampling. Mar. Pollut. Bull. 88(1-2), 325-333.

Lusher, A.L., Tirelli, V., O Connor, I., Officer, R., 2015. Microplastics in Arctic polar waters: the first reported values of particles in surface and sub-surface samples. Sci. Rep.-Uk 5(1).

Masura J, Baker JE, Foster GD, Arthur C, Herring C. Laboratory methods for the analysis of microplastics in the marine environment: recommendations for quantifying synthetic particles in waters and sediments. 2015.

Moore, C.J., 2008. Synthetic polymers in the marine environment: a rapidly increasing, long-term threat. Environ. Res. 108(2), 131-139. 
Morton, W. E, Hearle, J. W. S. 2008. Physical Properties of Textile Fibres (fourth edition). Woodhead Publishing Limited, Cambridge.

Nelms, S.E., Galloway, T.S., Godley, B.J., Jarvis, D.S., Lindeque, P.K., 2018. Investigating microplastic trophic transfer in marine top predators. Environ. Pollut. 238, 999-1007.

Ng, K.L., Obbard, J.P., 2006. Prevalence of microplastics in Singapore's coastal marine environment. Mar. Pollut. Bull. 52(7), 761-767.

Osswald, T. A., 2006. International Plastics Handbook: The Resource for Plastics Engineers. Hanser Gardner Publications, Ohio.

Oztekin, A., Bat, L., 2017. Microlitter Pollution in Sea Water: A Preliminary Study from Sinop Sarikum Coast of the Southern Black Sea. Turk. J. Fish. Aquat. Sc. 17(6).

Peng, X., Chen, M., Chen, S., Dasgupta, S., Xu, H., Ta, K., Du, M., Li, J., Guo, Z., Bai, S., 2018. Microplastics contaminate the deepest part of the world's ocean. Geochemical Perspectives Letters, $1-5$.

Reineccius, J., Appelt, J., Hinrichs, T., Kaiser, D., Stern, J., Prien, R.D., Waniek, J.J., 2020. Abundance and characteristics of microfibers detected in sediment trap material from the deep subtropical North Atlantic Ocean. Sci. Total Environ. 738, 140354.

Reisser, J., Slat, B., Noble, K., du Plessis, K., Epp, M., Proietti, M., de Sonneville, J., Becker, T., Pattiaratchi, C., 2015. The vertical distribution of buoyant plastics at sea: an observational study in the North Atlantic Gyre. Biogeosciences 12(4), 1249-1256.

Rowley, K.H., Cucknell, A., Smith, B.D., Clark, P.F., Morritt, D., 2020. London's river of plastic: High levels of microplastics in the Thames water column. Sci. Total Environ. 740, 140018.

Ryan, P.G., Suaria, G., Perold, V., Pierucci, A., Bornman, T.G., Aliani, S., 2020. Sampling microfibres at the sea surface: The effects of mesh size, sample volume and water depth. Environ. Pollut. 258, 113413.

Song, Y.K., Hong, S.H., Eo, S., Jang, M., Han, G.M., Isobe, A., Shim, W.J., 2018. Horizontal and Vertical Distribution of Microplastics in Korean Coastal Waters. Environ. Sci. Technol. 52(21), 12188-12197.

Sun, X., Liu, T., Zhu, M., Liang, J., Zhao, Y., Zhang, B., 2018. Retention and characteristics of microplastics in natural zooplankton taxa from the East China Sea. Sci. Total Environ. 640-641, 232-242. 
Sussarellu, R., Suquet, M., Thomas, Y., Lambert, C., Fabioux, C., Pernet, M.E.J., Le Goïc, N., Quillien, V., Mingant, C., Epelboin, Y., Corporeau, C., Guyomarch, J., Robbens, J., Paul-Pont, I., Soudant, P., Huvet, A., 2016. Oyster reproduction is affected by exposure to polystyrene microplastics. Proceedings of the National Academy of Sciences 113(9), 2430-2435.

Tamminga, M., Hengstmann, E., Fischer, E.K., 2018. Microplastic analysis in the South Funen Archipelago, Baltic Sea, implementing manta trawling and bulk sampling. Mar. Pollut. Bull. 128, $601-608$.

Tekman, M.B., Wekerle, C., Lorenz, C., Primpke, S., Hasemann, C., Gerdts, G., Bergmann, M., 2020. Tying up Loose Ends of Microplastic Pollution in the Arctic: Distribution from the Sea Surface through the Water Column to Deep-Sea Sediments at the HAUSGARTEN Observatory. Environ. Sci. Technol. 54(7), 4079-4090.

Thompson, R.C., Olsen, Y., Mitchell, R.P., Davis, A., Rowland, S.J., John, A.W., McGonigle, D., Russell, A.E., 2004. Lost at sea: where is all the plastic? Science 304(5672), 838.

van Sebille, E., Aliani, S., Law, K.L., Maximenko, N., Alsina, J., Bagaev, A., Bergmann, M., Chapron, B., Chubarenko, I., Cózar, A., Delandmeter, P., Egger, M., Fox-Kemper, B., Garaba, S.P., Goddijn-Murphy, L., Hardesty, D., Hoffman, M.J., Isobe, A., Jongedijk, C., Kaandorp, M., Khatmullina, L., Koelmans, A.A., Kukulka, T., Laufkötter, C., Lebreton, L., Lobelle, D., Maes, C., Martinez-Vicente, V., Morales Maqueda, M.A., Poulain-Zarcos, M., Rodriguez, E., Ryan, P.G., Shanks, A., Shim, W.J., Suaria, G., Thiel, M., van den Bremer, T., Wichmann, D., 2020. The physical oceanography of the transport of floating marine debris. Environ. Res. Lett. 15(2), 23003-23032. van Sebille, E., Aliani, S., Law, K.L., Maximenko, N., Alsina, J.M., Bagaev, A., Bergmann, M., Chapron, B., Chubarenko, I., Cózar, A., Delandmeter, P., Egger, M., Fox-Kemper, B., Garaba, S.P., Goddijn-Murphy, L., Hardesty, B.D., Hoffman, M.J., Isobe, A., Jongedijk, C.E., Kaandorp, M.L.A., Khatmullina, L., Koelmans, A.A., Kukulka, T., Laufkötter, C., Lebreton, L., Lobelle, D., Maes, C., Martinez-Vicente, V., Morales Maqueda, M.A., Poulain-Zarcos, M., Rodríguez, E., Ryan, P.G., Shanks, A.L., Shim, W.J., Suaria, G., Thiel, M., van den Bremer, T.S., Wichmann, D., 2020. The physical oceanography of the transport of floating marine debris. Environ. Res. Lett. 15(2), 2300323032.

Wang, W., Yuan, W., Chen, Y., Wang, J., 2018. Microplastics in surface waters of Dongting Lake and Hong Lake, China. Sci. Total Environ. 633, 539-545. 

microplastic debris. Roy. Soc. Open. Sci 1(4), 140317.

Zhao, S., Zhu, L., Wang, T., Li, D., 2014. Suspended microplastics in the surface water of the Yangtze Estuary System, China: First observations on occurrence, distribution. Mar. Pollut. Bull.

664

665

666

667



Figure list:

Fig.1 Geolocation of sampled water columns for MPs research (A). Red dots indicate the geographical locations of sampling sites in collected literatures except for Ryan et al, 2020 due to limited accessible information. Sampling device used for collecting MPs in the water column (B: CTD sampler; C: plexiglass water sampler; D: submersible pump; E: plankton net; F: multinet trawls; G: lander system; H: plankton pump; I: remotely operated vehicle (ROV)). 86(1-2), 562-568.

Zhao, S., Wang, T., Zhu, L., Xu, P., Wang, X., Gao, L., Li, D., 2019. Analysis of suspended microplastics in the Changjiang Estuary: Implications for riverine plastic load to the ocean. Water Res. 161, 560-569.

Zobkov, M.B., Esiukova, E.E., Zyubin, A.Y., Samusev, I.G., 2019. Microplastic content variation in water column: The observations employing a novel sampling tool in stratified Baltic Sea. Mar. Pollut. Bull. 138, 193-205.

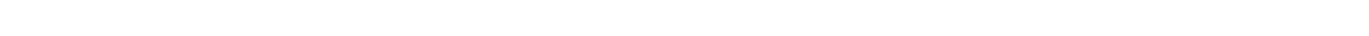


691

692

693

694

695

696

697

698

699

700

701 Table list:

702

703 Table.1 Sampling information of MPs in the water column from literatures

704

705 Table.2 Characteristics summary of MPs in the water columns from literatures

706

707 Table.3 Polymer type, its abbreviation, density of observed MPs in the water column from reference

$708 \quad(\mathrm{~N}=17)$

709

710

711

712

713

Table.1 Sampling information of MPs in the water column from literatures

\begin{tabular}{|c|c|c|c|c|c|c|}
\hline Sampling regions & Methods & depth (m) & $\begin{array}{l}\text { volume } \\
\text { /sample(L) }\end{array}$ & $\begin{array}{l}\text { Mesh size of nets }{ }^{a} \text { or } \\
\text { filters (sieves) }{ }^{b}(\mu \mathrm{m})\end{array}$ & $\begin{array}{l}\text { Samples pretreatment } \\
\text { and polymer analysis }\end{array}$ & $\begin{array}{l}\text { MPs size } \\
(\mathrm{mm})\end{array}$ \\
\hline $\begin{array}{l}\text { South China Sea, China } \\
\text { (Ding et al., 2019) }\end{array}$ & $\begin{array}{l}\text { plexiglass } \\
\text { water sampler }\end{array}$ & 5 and 15 & 5 & $0.45^{\mathrm{b}}$ & $\begin{array}{l}\text { Direct filtration; } \\
\mu \text {-FT-IR spectrometer }\end{array}$ & $\begin{array}{l}0.02-0.33 \\
(\text { mostly })^{\mathrm{c}}\end{array}$ \\
\hline $\begin{array}{l}\text { South China Sea, China } \\
\text { (Ding et al., 2019) }\end{array}$ & \multirow{3}{*}{ CTD sampler } & $10-40$ & 5 & $0.45^{\mathrm{b}}$ & $\begin{array}{l}\text { Direct filtration; } \\
\mu \text {-FT-IR spectrometer }\end{array}$ & $\begin{array}{l}0.02-0.33 \\
(\text { mostly) }\end{array}$ \\
\hline $\begin{array}{l}\text { Arctic Central Basin } \\
\text { (Kanhai et al., 2018) }\end{array}$ & & $8-4,369$ & $7-48$ & $250^{\mathrm{b}} ; 1.20^{\mathrm{b}}$ & $\begin{array}{l}\text { Direct filtration; } \\
\mu \text {-FT-IR spectrometer }\end{array}$ & $0.25-5.00$ \\
\hline Mariana Trench & & $2,673-10,903$ & $35-180$ & $0.22^{\mathrm{b}} ; 0.30^{\mathrm{b}}$ & Direct filtration; & $1.00-3.00$ \\
\hline
\end{tabular}


(Peng et al., 2018)

Baltic Sea proper

(Bagaev et al., 2017)

Baltic Sea

(Bagaev et al., 2018)

(.....................

Bohai sea, China

(Dai et al., 2018)

\section{Sumba coastal waters,}

Indonesia

(Cordova et al., 2018)

Northern Gulf of

Mexico

(Di Mauro et al., 2017)

Baltic Sea, Sweden
(Gorokhova, 2015)

Sarıkum Lagoon, Black

Sea

(Oztekin et al., 2015)

\section{River Thames}

(Rowley et al., 2020)

Tuscany coastal waters,

Mediterranean Sea

(Baini et al., 2018)

Turkish coastal waters, Plankton net Mediterranean Sea

(Güven et al., 2017)

\section{Gulf of Lions}

(Lefebvre et al., 2019)

Northern Gulf of

Mexico

(Di Mauro et al., 2017)

Southeast Bering Sea

(Doyle et al., 2011)

Northeast Pacific

(Goldstein et al., 2013)

Santa Monica Bay multi-net
$0.5-217.5$

$7.79-30$

$174^{b}$

$0-217.5$

10 or 30

$174^{b}$

Raman spectroscopy

(mostly)

Direct filtration;

Combination of visual

identification and UV

N/A ${ }^{d}$

lamp

Direct filtration;

Elastic property

$\mathrm{N} / \mathrm{A}^{\mathrm{d}}$

determination

Concentrate the sample

with $5 \mu \mathrm{m}$ porosity

filters and remove the

$0.10-3.00$

$0-30$

5

$5^{\text {b }} ; 20^{\mathrm{b}}$

organics prior to next

(mostly) ${ }^{\mathrm{c}}$

filtration $(20 \mu \mathrm{m})$;

$\mu$-FT-IR spectrometer

Direct filtration;

$0.30-1.00$

5-300

10

$0.45^{b}$

FT-IR spectrometer

$(\text { mostly })^{\mathrm{c}}$

$\begin{array}{lll}2.2-53.5 & 5 & 0.70^{\mathrm{b}}\end{array}$

$0.70^{\mathrm{b}}$

Direct filtration;

FT-IR spectrometer

$\mathrm{N} / \mathrm{A}^{\mathrm{d}}$

Direct observation;

0.05-0.30

visual identification (mostly) ${ }^{\mathrm{c}}$

Direct filtration;

$0-30$

$\mathrm{N} / \mathrm{A}^{\mathrm{d}}$

$300^{\mathrm{a}} ; 1.20^{\mathrm{b}}$

No polymeric

$\mathrm{N} / \mathrm{A}^{\mathrm{d}}$

identification

Organics removal prior

$0-2$

$\mathrm{N} / \mathrm{A}^{\mathrm{d}}$

$250^{\mathrm{a}} ; 32-1,000^{\mathrm{b}}$

to direct observation;

$0.03-5.00$

FT-IR spectrometer

$2-120 \quad 500-30,000 \quad 200$

Direct observation;

$1-2.5$

FT-IR spectrometer

$(\text { mostly })^{\mathrm{c}}$

Organics removal prior

$0-55 \quad N / A^{d} \quad 200^{a} ; 26^{b}$

to direct observation;

$0.1-2.5$

FT-IR spectrometer

(mostly) $^{\mathrm{c}}$

$\begin{array}{llll}0-100 & N / A^{d} & 200^{a} & \begin{array}{l}\text { Direct observation; } \\ \text { FT-IR spectrometer }\end{array}\end{array}$

0-15

$\begin{aligned} & 12,800- \\ & 64,100\end{aligned} 335^{\text {a }} ; 50^{\text {b }}$

Direct observation;

FT-IR spectrometer

$\mathrm{N} / \mathrm{A}^{\mathrm{d}}$

\begin{tabular}{|c|c|c|c|c|}
\hline $0-212$ & $\mathrm{~N} / \mathrm{A}^{\mathrm{d}}$ & $505^{\mathrm{a}}$ & $\begin{array}{l}\text { Direct observation; } \\
\text { FT-IR spectrometer }\end{array}$ & $\mathrm{N} / \mathrm{A}^{\mathrm{d}}$ \\
\hline $0-210$ & $\mathrm{~N} / \mathrm{A}^{\mathrm{d}}$ & $202^{a}$ & $\begin{array}{l}\text { Direct observation; } \\
\text { FT-IR spectrometer }\end{array}$ & $\mathrm{N} / \mathrm{A}^{\mathrm{d}}$ \\
\hline $0-14.80$ & $\mathrm{~N} / \mathrm{A}^{\mathrm{d}}$ & $333^{a}$ & Freshwater floatation; & $2.80-4.75$ \\
\hline
\end{tabular}




\begin{tabular}{|c|c|c|c|c|c|c|}
\hline (Lattin et al., 2004) & trawls & & & & $\begin{array}{l}\text { No polymeric } \\
\text { identification }\end{array}$ & $(\text { mostly })^{\mathrm{c}}$ \\
\hline $\begin{array}{l}\text { Milwaukee River Basin } \\
\text { (Lenaker et al., 2019) }\end{array}$ & & $0-15.50$ & $\mathrm{~N} / \mathrm{A}^{\mathrm{d}}$ & $333^{\mathrm{a}} ; 355-4,750^{\mathrm{b}}$ & $\begin{array}{l}\text { Organics removal prior } \\
\text { to the filtration; } \\
\text { FTIR spectrometer and } \\
\text { py-GCMS }\end{array}$ & $\begin{array}{l}0.36-1.00 \\
(\text { mostly) }\end{array}$ \\
\hline $\begin{array}{l}\text { North Atlantic } \\
\text { accumulation } \\
\text { Zone } \\
\text { (Kooi et al., 2016) }\end{array}$ & & $0-5.5$ & $\mathrm{~N} / \mathrm{A}^{\mathrm{d}}$ & $330^{\mathrm{a}} ; 500-5,000^{\mathrm{b}}$ & $\begin{array}{l}\text { saltwater floatation; } \\
\text { No polymeric } \\
\text { identification }\end{array}$ & $0.50-5.00$ \\
\hline $\begin{array}{l}\text { North Atlantic } \\
\text { subtropical gyre } \\
\text { (Kukulka et al., 2012) }\end{array}$ & & $5-20$ & $\mathrm{~N} / \mathrm{A}^{\mathrm{d}}$ & $\mathrm{N} / \mathrm{A}^{\mathrm{d}}$ & $\mathrm{N} / \mathrm{A}^{\mathrm{d}}$ & $\mathrm{N} / \mathrm{A}^{\mathrm{d}}$ \\
\hline $\begin{array}{l}\text { North Atlantic Gyre } \\
\text { (Reisser et al., 2015) }\end{array}$ & & $0-5$ & $\mathrm{~N} / \mathrm{A}^{\mathrm{d}}$ & 150 a; & $\begin{array}{l}\text { seawater floatation; } \\
\text { No polymeric } \\
\text { identification }\end{array}$ & $0.50-5.00$ \\
\hline $\begin{array}{l}\text { Austrian Danube River } \\
\text { (Liedermann et al., } \\
\text { 2018) }\end{array}$ & & $\mathrm{N} / \mathrm{A}^{\mathrm{d}}$ & $\mathrm{N} / \mathrm{A}^{\mathrm{d}}$ & $500^{\mathrm{a}}$ & $\begin{array}{l}\mathrm{NaCl} \text { solution floatation } \\
\text { prior to the refiltration; } \\
\text { FT-IR spectrometer }\end{array}$ & $\mathrm{N} / \mathrm{A}^{\mathrm{d}}$ \\
\hline $\begin{array}{l}\text { North Pacific Garbage } \\
\text { Patch } \\
\text { (Egger et al., 2020) }\end{array}$ & $\begin{array}{l}\text { Multiple } \\
\text { Opening and } \\
\text { Closing Net }\end{array}$ & $0-2,002$ & $\begin{array}{l}136,000- \\
5,039,000\end{array}$ & $333^{\mathrm{a}} ; 500-15,000^{\mathrm{b}}$ & $\begin{array}{l}\text { Direct observation; } \\
\text { Raman spectroscopy }\end{array}$ & $\mathrm{N} / \mathrm{A}^{\mathrm{d}}$ \\
\hline $\begin{array}{l}\text { Svalbard archipelago, } \\
\text { Norway } \\
\text { (Lusher et al., 2015) }\end{array}$ &  & $\begin{array}{l}0 \quad \text { (manta } \\
\text { trawl) and } 6\end{array}$ & 2,000 & $250^{\mathrm{b}} ; 1.2^{\mathrm{b}}$ & $\begin{array}{l}\text { Direct filtration; } \\
\text { FT-IR spectrometer }\end{array}$ & $0.25-5.00$ \\
\hline $\begin{array}{l}\text { Southern Ocean, } \\
\text { Atlantic Ocean, Indian } \\
\text { Ocean and } \\
\text { Mediterranean Sea } \\
\text { (Ryan et al., 2020) }\end{array}$ & $\begin{array}{l}\text { water intake } \\
\text { system }\end{array}$ & $\begin{array}{l}0 \quad \text { (metal } \\
\text { bucket) and } 5\end{array}$ & $10-20$ & $0.70^{\mathrm{b}}$ & $\begin{array}{l}\text { Direct filtration; } \\
\text { No polymeric } \\
\text { identification }\end{array}$ & $\mathrm{N} / \mathrm{A}^{\mathrm{d}}$ \\
\hline $\begin{array}{l}\text { Singapore coastal waters } \\
(\mathrm{Ng} \text { and Obbard, 2006) }\end{array}$ & & $\begin{array}{l}0 \quad \text { (Rotating } \\
\text { drum sampler) } \\
\mathrm{e} \text { and } 1\end{array}$ & 10 & $1.6^{\mathrm{b}}$ & $\begin{array}{l}\text { Direct filtration; } \\
\text { FT-IR spectrometer }\end{array}$ & $\mathrm{N} / \mathrm{A}^{\mathrm{d}}$ \\
\hline $\begin{array}{l}\text { Baltic Sea, Russia } \\
\text { (Zobkov et al., 2019) }\end{array}$ & $\begin{array}{l}\text { submersible } \\
\text { pump }\end{array}$ & $0.5-91$ & $2,500-3,500$ & $174^{b}$ & $\begin{array}{l}\text { Organics removal prior } \\
\text { to the refiltration } \\
(174 \mu \mathrm{m}) \text {; } \\
\mu \text {-Raman spectroscopy }\end{array}$ & $\begin{array}{l}0.17-1.00 \\
(\text { mostly) }\end{array}$ \\
\hline $\begin{array}{l}\text { Korean coastal waters } \\
\text { (Song et al., 2018) }\end{array}$ & & $3-58$ & 100 & $20^{b} ; 5^{b}$ & $\begin{array}{l}\mathrm{NaCl} \text { solution floatation } \\
\text { prior to the refiltration; } \\
\mu \text {-FT-IR spectrometer }\end{array}$ & $0.02-5.00$ \\
\hline $\begin{array}{l}\text { East China Sea } \\
\text { (Liu et al., 2019) }\end{array}$ & In-situ & 4 & $\begin{array}{l}1,000- \\
16,000\end{array}$ & $60^{\mathrm{a}} ; 1.60^{\mathrm{b}}$ & $\begin{array}{l}\text { Organics removal prior } \\
\text { to the filtration; } \\
\mu \text {-FT-IR spectrometer }\end{array}$ & $\mathrm{N} / \mathrm{A}^{\mathrm{d}}$ \\
\hline Monterey Bay & & $5-1,000$ & $1,007-2,378$ & $100^{\mathrm{b}}$ & Direct observation; & $\mathrm{N} / \mathrm{A}^{\mathrm{d}}$ \\
\hline
\end{tabular}




\begin{tabular}{|c|c|c|c|c|c|}
\hline (Choy et al., 2019) & & & & Raman spectroscopy & \\
\hline HAUSGARTEN & & & & Organics removal prior & \\
\hline $\begin{array}{l}\text { observatory } \\
\text { (Tekman et al., 2020) }\end{array}$ & $1-5,350$ & $218-561$ & $32^{b}$ & $\begin{array}{l}\text { to the filtration; } \\
\mu \text {-FT-IR spectrometer }\end{array}$ & $0.01-0.15$ \\
\hline
\end{tabular}

714 a: mesh size of net used in the reference.

715 b: mesh size of filter or sieve used in filtering process.

716 c: only size range of MPs was presented in the literature.

$717 \mathrm{~d}$ : N/A represented no available information.

718 e: during the investigation in Singapore coastal waters, $\mathrm{Ng}$ and Obbard (2006) sampled 50-60 $\mu \mathrm{m}$ depth in the surface

719 using a rotating drum sampler and it could be considered as surface sampling due to the proximity to the air-sea

720 interaction surface. 
Table.2 Characteristics summary of MPs in the water columns from literatures

\begin{tabular}{|c|c|c|c|c|c|c|c|c|c|}
\hline \multirow{2}{*}{ Region division } & \multirow{2}{*}{ Study area } & \multirow{2}{*}{$\begin{array}{l}\text { Sampling } \\
\text { methods }\end{array}$} & \multicolumn{6}{|c|}{ Shape composition of MPs } & \multirow{2}{*}{ Major findings } \\
\hline & & & Fiber & Fragment & Granule & Foam & Film & Microbead & \\
\hline \multirow{3}{*}{ Freshwater system } & River Thames & Bulk sampling & Exclude $^{b}$ & Detect $^{b}$ & Detect $^{b}$ & - & Detect $^{b}$ & Detect $^{b}$ & $\begin{array}{l}\text { The abundance of MPs varied with } \\
\text { sampling month, location and depth }\end{array}$ \\
\hline & Milwaukee River Basin & Net sampling & $89 \%$ & $8 \%$ & $0.40 \%$ & $1 \%$ & $2 \%$ & - & $\begin{array}{l}\text { Significant variation of shape } \\
\text { composition was not found offshore }\end{array}$ \\
\hline & Austrian Danube River & Net sampling & - & - & - & - & - & - & $\begin{array}{l}\text { A new methodology for MPs in the } \\
\text { water column was established; } 500 \\
\mu \mathrm{m} \text { mesh size of net was } \\
\text { recommended }\end{array}$ \\
\hline \multirow{5}{*}{ Coastal waters } & Bohai sea, China & Bulk sampling & $91 \%$ & $9 \%$ & - & - & - & - & $\begin{array}{l}\text { Numerical proportion of fibrous MPs } \\
\text { is lower than surface water; Content } \\
\text { of MPs }<300 \mu \mathrm{m} \text { increase with } \\
\text { depth. }\end{array}$ \\
\hline & South China Sea, China & Bulk sampling & $80 \%$ & $13 \%$ & $5 \%$ & - & $2 \%$ & - & $\begin{array}{l}\text { The number of MPs would decrease } \\
\text { with depth, and peak at the } \\
\text { subsurface }\end{array}$ \\
\hline & Baltic Sea proper & Bulk sampling & Detect $^{b}$ & Detect $^{b}$ & - & - & Detect $^{b}$ & - & $\begin{array}{l}\text { More abundant fibrous MPs would be } \\
\text { found near surface and bottom water } \\
\text { than intermediate water }\end{array}$ \\
\hline & $\begin{array}{l}\text { Sumba coastal waters, } \\
\text { Indonesia }\end{array}$ & Bulk sampling & $45 \%$ & - & $36 \%$ & - & - & - & $\begin{array}{l}\text { Most of MPs was found above the } \\
\text { thermocline. }\end{array}$ \\
\hline & $\begin{array}{l}\text { Northern Gulf of } \\
\text { Mexico }\end{array}$ & Bulk sampling & Detect $^{b}$ & Detect $^{b}$ & & & & Detect $^{b}$ & $\begin{array}{l}\text { No significant relationship between } \\
\text { MPs abundance and sampling was }\end{array}$ \\
\hline
\end{tabular}









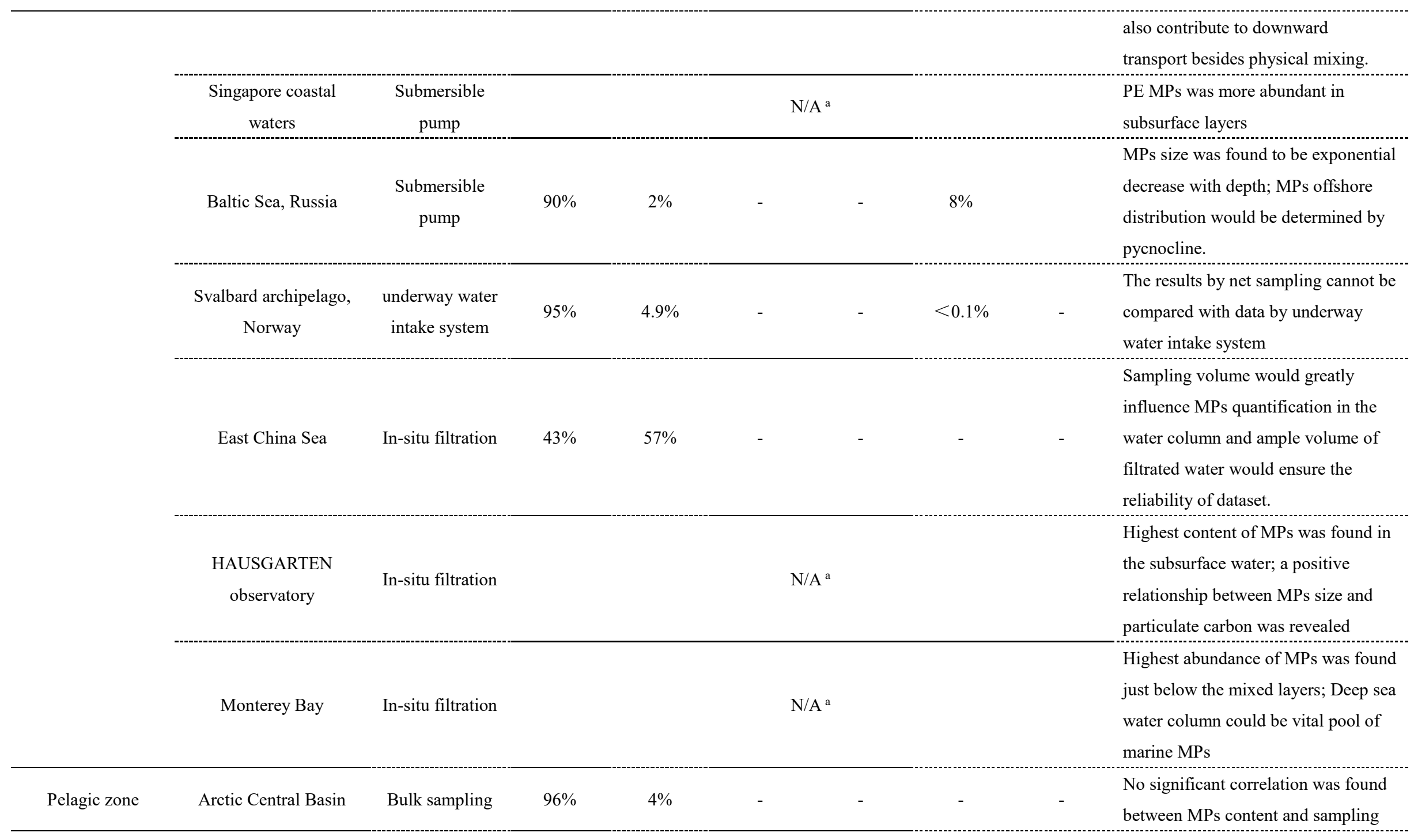


depth.

\begin{tabular}{|c|c|c|c|c|c|c|c|c|}
\hline Mariana Trench & Bulk sampling & Majority ${ }^{b}$ & A little ${ }^{b}$ & A little ${ }^{b}$ & - & - & - & $\begin{array}{l}\text { The hadal zone could be the largest } \\
\text { sink of marine plastic debris; Linear } \\
\text { relationship between MPs abundance } \\
\text { and depth }\end{array}$ \\
\hline $\begin{array}{c}\text { North Atlantic } \\
\text { accumulation zone }\end{array}$ & Net sampling & Detect $^{b}$ & Detect $^{b}$ & Detect $^{b}$ & - & - & - & $\begin{array}{l}\text { Numerical abundance and mass } \\
\text { concentration of MPs would } \\
\text { exponentially decrease with depth }\end{array}$ \\
\hline $\begin{array}{l}\text { North Atlantic } \\
\text { subtropical gyre }\end{array}$ & Net sampling & & & & & & & $\begin{array}{l}\text { Vertical transport of plastic debris } \\
\text { could mainly result from wind-driven } \\
\text { mixing }\end{array}$ \\
\hline North Atlantic Gyre & Net sampling & Detect $^{b}$ & Most $^{b}$ & Detect $^{b}$ & Detect $^{b}$ & - & - & $\begin{array}{l}\text { Mass concentration of plastic debris } \\
\text { would exponentially decrease with } \\
\text { depth; sink rate have a close } \\
\text { relationship with sea state. }\end{array}$ \\
\hline $\begin{array}{c}\text { North Pacific Garbage } \\
\text { Patch }\end{array}$ & Net sampling & Detect $^{b}$ & Detect $^{b}$ & - & - & - & - & $\begin{array}{l}\text { Mass concentration of plastic } \\
\text { fragment decrease with depth }\end{array}$ \\
\hline Northeast Pacific & Net sampling & - & - & - & - & - & - & $\begin{array}{c}\text { Most of MPs was observed on } \\
\text { surface water }\end{array}$ \\
\hline
\end{tabular}

a: N/A indicated no available information.

723 b: Numerical proportion was not clearly presented in the study. 

reference $(\mathrm{N}=17)$

\begin{tabular}{|c|c|c|c|}
\hline Polymer types & Abbreviation & Reference density $\left(\mathrm{g} / \mathrm{cm}^{3}\right)^{a}$ & Number of studies $(\mathrm{N})$ \\
\hline polyethylene & $\mathrm{PE}$ & $0.92-0.96$ & 15 \\
\hline polypropylene & PP & $0.90-0.92$ & 13 \\
\hline polyethylene terephthalate & PET & 1.34 & 12 \\
\hline polyamide & PA & $1.02-1.14$ & 11 \\
\hline polyvinyl chloride & PVC & $1.38-1.41$ & 11 \\
\hline polystyrene & PS & 1.05 & 10 \\
\hline poly (methyl methacrylate) & PMMA & $1.17-1.20$ & 6 \\
\hline acrylonitrile butadiene styrene & ABS & $1.04-1.06$ & 3 \\
\hline polyacrylonitrile & PAN & $1.19^{\mathrm{b}}$ & 3 \\
\hline polyurethane & PU & 1.05 & 3 \\
\hline polycarbonate & $\mathrm{PC}$ & 1.2 & 3 \\
\hline ethylne vinyl acetate & EVA & $0.92-0.95$ & 3 \\
\hline polyvinylidene fluoride & PVDF & $1.76-1.78$ & 2 \\
\hline alkyd resin & ALK & $1.42-2.20$ & 2 \\
\hline poly (vinyl alcohol) & PVAL & $1.2-1.3$ & 2 \\
\hline polycaprolactone & PCL & - & 2 \\
\hline phenolic resin & $\mathrm{PF}$ & $1.25-1.30$ & 1 \\
\hline polyvinyl methyl ether & PVME & - & 1 \\
\hline polyterpene resins & PTR & - & 1 \\
\hline polylactide & PLA & 1.25 & 1 \\
\hline polystyrene acrylonitrile & SAN & 1.08 & 1 \\
\hline poly (butyl methacrylate) & PBMA & 1.07 & 1 \\
\hline poly (acrylate: styrene) & PAS & - & 1 \\
\hline polyoxymethylene & POM & $1.41-1.42$ & 1 \\
\hline epoxy resin & EP & 1.9 & 1 \\
\hline polyvinyl acetate & PVAc & 1.19 & 1 \\
\hline polybutadiene acrylonitrile & PBAN & - & 1 \\
\hline polydimethylsiloxane & PDMS & 0.98 & 1 \\
\hline polyacrylamide & PAM & - & 1 \\
\hline polyepichlorohydrin & - & - & 1 \\
\hline polytetrafluoroethylene & PTFE & $2.13-2.33$ & 1 \\
\hline phenoxy resin & Phe & - & 1 \\
\hline thermoplastic rubber & - & - & 1 \\
\hline Styrene butadiene & $\mathrm{SB}$ & $1.03-1.04$ & 1 \\
\hline ethylene-propylene-diene rubber & EPDM & - & 1 \\
\hline nitrile rubber & NBR & - & 1 \\
\hline polysulfone & PSU & $1.24-1.25$ & 1 \\
\hline copolymer $^{\mathrm{c}}$ & $\mathrm{CM}$ & - & 4 \\
\hline
\end{tabular}


Limited, Cambridge.

733

c: copolymer or blends was only reported in the Arctic Central Basin (Kanhai et al., 2018), the Bohai Sea (Dai et al.,

734 2018), South China Sea (Ding et al., 2019) and River Thames (Rowley et al., 2020)

735

736

737 